\title{
Drying kinetics of fresh and osmotically pre-treated papaya (Carica papaya L.)
}

\author{
Ânoar Abbas El-Aouar *, Patrícia Moreira Azoubel, Fernanda Elizabeth Xidieh Murr \\ Department of Food Engineering, College of Food Engineering, State University of Campinas, P.O. Box 6121, ZIP 13083-970 Campinas, SP, Brazil \\ Received 7 June 2002; accepted 24 October 2002
}

\begin{abstract}
The aim of this work was to study and to model the drying kinetics of fresh and osmotically pre-treated papaya cubes (Carica papaya L.) using the diffusional model (Fick's second law) adapted to a cubic geometry, and an empirical two parameters model. The osmotic pre-treatment was carried out in an incubator at constant temperature and agitation. The drying process was carried out in a fixed bed dryer at two different temperatures and air velocities. At the beginning of the drying process of fresh papaya, drying rate was influenced by both air velocity and air temperature. But lose to the equilibrium condition, the drying rate was affected only by the air temperature. The physico-chemical changes in the papaya cubes during osmotic pre-treatment caused differences in the drying rate in the subsequent air drying process when compared to fresh papaya cubes. The effective diffusivities of water, calculated by diffusional model, were of the order of $10^{-9} \mathrm{~m}^{2} / \mathrm{s}$.
\end{abstract}

(c) 2003 Elsevier Science Ltd. All rights reserved.

Keywords: Papaya; Osmotic dehydration; Drying; Effective diffusivity

\section{Introduction}

Foodstuffs quality and the cost of their manufacture are the most important factors to be considered when choosing a food preservation method. Water, being one of the main food components, has a decisive direct influence on the quality and durability of foodstuffs through its effect on many physico-chemical and biological changes. Water removal or making water hard to access for microbe development is the main task while preserving food (Lenart, 1996).

In the course of the last few years a number of activities have been undertaken in order to apply drying for preservation of food (especially of solid food) as widely as possible. Conventional drying is a simultaneous heat and mass transfer process, accompanied by phase change (Barbanti, Mastrocola, \& Severini, 1994). The factors that govern the transfer mechanisms determine the drying rate. These factors are: vapour pressure of the material and drying air, air velocity and tempe-

\footnotetext{
${ }^{*}$ Corresponding author. Tel.: +55-19-3788-4057; fax: +55-19-37884027.

E-mail address: anoar@ceres.fea.unicamp.br (Â.A. El-Aouar).
}

rature, water diffusion velocity in the material, thickness and surface exposed for drying (Van Arsdel, 1973).

Dried food, especially fruits and vegetables, can be stored and transported at a relatively low cost. However, water removal leads to a serious decrease in the nutritive and sensorial values (Lenart, 1996). One of the research objectives is to achieve the best possible quality of the final product.

Osmotic dehydration is a useful technique that involves product immersion in a hypertonic aqueous solution leading to a loss of water through the cell membranes of the product and subsequent flow along the inter-cellular space before diffusing into the solution (Sereno, Moreira, \& Martinez, 2001). For fruit dehydration, sucrose solutions with concentrations from 50 to $70^{\circ}$ Brix have been used (Lerici, Pinnavaia, Dalla Rosa, \& Bartolucci, 1985). The Osmotic process has received considerable attention as a pre-drying treatment so as to reduce energy consumption and improve food quality (Jayaraman \& Das Gupta, 1992; Karathanos, Kostaropoulos, \& Saravacos, 1995; Sereno et al., 2001; Torreggiani, 1993). As part of the process of fruit and vegetable concentration, after osmotic dehydration, a complementary method, such as conventional drying, freezing or pasteurization, must be used (Sankat, 
Castaigne, \& Maharaj, 1996). According to Pokharkar, Prasad, and Das (1997), the main advantages of the osmotic dehydration process as a pre-treatment are: inhibition of enzymatic browning, retention of natural colour without addition of sulphites and high retention of volatile compounds during subsequent drying.

Therefore, the aim of this work was to study and to model the drying kinetics of fresh and osmotically pretreated papaya using the diffusional model, adapted to a cubic geometry, and an empirical two parameters model.

\section{Theory}

An infinite slab of thickness $2 \mathrm{~L}$ having the uniform initial water amount, undergoing drying under constant conditions can be described by Fick's unidirectional diffusion equation (Crank, 1975):

$\frac{\partial \mathrm{WA}(t)}{\partial t}=\frac{\partial}{\partial z}\left(D_{\mathrm{eff}} \frac{\partial \mathrm{WA}(t)}{\partial z}\right)$

Using the following initial and boundary conditions:

uniform initial amount: $\mathrm{WA}(z, 0)=\mathrm{WA}_{0}$,

symmetry of concentration: $\left.\frac{\partial \mathrm{WA}(t)}{\partial z}\right|_{z=0}=0$,

equilibrium content at surface: $\mathrm{WA}(L, t)=\mathrm{WA}_{\infty}$

and applying:

$\overline{\mathrm{WA}(t)}=\frac{1}{L} \int_{0}^{L} \mathrm{WA}(z, t) \mathrm{d} z$

Therefore, the solution as a series obtained for water transport in a cubic solid corresponds to the product of three perpendicular infinite slabs solutions (Crank, 1975; Treybal, 1981):

$W=\frac{8}{\pi^{2}}\left(\sum_{i=0}^{\infty} \frac{1}{(2 i+1)^{2}} \exp \left(-(2 i+1)^{2} \pi^{2} D_{\text {eff }} \frac{t}{4 L^{2}}\right)\right)^{3}$

where $D_{\text {eff }}$ is the effective diffusivity of water $\left(\mathrm{m}^{2} / \mathrm{s}\right), i$ is the number of series terms, $L$ is the characteristic length, sample half-thickness (m), $t$ is the drying time (s), $W$ is the dimensionless amount of water defined by Eq. (4).

$W=\frac{\overline{\mathrm{WA}(t)}-\mathrm{WA}_{\infty}}{\mathrm{WA}_{0}-\mathrm{WA}_{\infty}}$

where $\mathrm{WA}_{0}$ is the initial water amount $(\mathrm{g}), \mathrm{WA}_{\infty}$ is the equilibrium water amount $(\mathrm{g})$ and $\overline{\mathrm{WA}(t)}$ is the average water amount at instant $t(\mathrm{~g})$.
Eq. (3) can be used in terms of moisture content:

$$
\begin{aligned}
M & =\frac{\overline{X(t)}-X_{\infty}}{X_{0}-X_{\infty}} \\
& =\frac{8}{\pi^{2}}\left(\sum_{i=0}^{\infty} \frac{1}{(2 i+1)^{2}} \exp \left(-(2 i+1)^{2} \pi^{2} D_{\text {eff }} \frac{t}{4 L^{2}}\right)\right)^{3}
\end{aligned}
$$

where $M$ is the dimensionless moisture ratio, $X_{0}$ is the initial moisture content ( $\mathrm{g}$ water/100 $\mathrm{g}$ dry matter), $X_{\infty}$ is the equilibrium moisture content ( $\mathrm{g}$ water/100 $\mathrm{g}$ dry matter), and $\overline{X(t)}$ is the average moisture content at instant $t$ (g water/100 g dry matter).

One of the most useful empirical models is Page's equation (Page, 1949), which is an empirical modification of the simple exponential model. It is written in the form:

$M=\frac{X(t)-X_{\infty}}{X_{0}-X_{\infty}}=\exp \left(-K t^{B}\right)$

where $K$ is the drying constant, $B$ is the Page's parameter and $t$ is the process time (s).

\section{Material and methods}

\subsection{Raw material}

The papayas (Carica papaya L.) of similar maturity $\left(10-12^{\circ}\right.$ Brix) and weight $(3.5-4.0 \mathrm{~kg})$ were purchased in a local market (CEASA of Campinas-SP, Brazil). The fruits were hand-peeled and cut into cubes $(20 \mathrm{~mm}$ side length) using a cutter designed for this purpose.

\subsection{Osmotic pre-treatment}

A $70^{\circ}$ Brix sucrose solution containing appropriate amounts of sodium lactate $2.4 \% \mathrm{w} / \mathrm{w}$ and lactic acid $0.1 \mathrm{M}$ was prepared. According to Rodrigues (1999), working with osmotic dehydration of papaya, such additives (sodium lactate and lactic acid) caused a final product with accentuated colour and instrumental texture similar to fresh fruit. The solution was translucent and without suspended particles and its concentration was verified using a refractometer.

Papaya cubes, previously weighed and identified, were placed into $250 \mathrm{~mL}$ beakers, containing the osmotic solution. A fruit/solution ratio of 1:10 was used. Papaya samples were placed in an incubator (TECNAL TE-421), maintained at $30^{\circ} \mathrm{C}$ and agitation at $110 \mathrm{rpm}$. After $4 \mathrm{~h}$ of experiment, samples were lightly rinsed to remove any excess sugar solution, drained and then placed on a pre-weighed drying tray in order to proceed to the drying process. 


\subsection{Air-drying experiments with fresh and osmotically pre-dehydrated papaya cubes}

A continuous flow fixed bed dryer was used and the tests were conducted at two different air velocities (1.25 and $3.25 \mathrm{~m} / \mathrm{s}$ ) and temperatures $\left(40\right.$ and $\left.60{ }^{\circ} \mathrm{C}\right)$. The dryer system consisted of vertical air flow through trays and was arranged as a closed circuit. For the air heating, three electric resistances were used (two of $1600 \mathrm{~W}$ and one of $800 \mathrm{~W}$ ), which could be worked independently, controlled by a digital thermostat. A thermal-hygrometer (TESTO 635) was used in order to measure the dry bulb temperature as well as the drying air humidity. A digital anemometer (AIRFLOW Co. LCS 6000) was used to measure the drying air velocity.

Samples had an average initial moisture content of $87.73 \%$ wet basis which was gravimetrically measured using a vacuum oven $(635 \mathrm{~mm} \mathrm{Hg})$ at $60{ }^{\circ} \mathrm{C}$ for $24 \mathrm{~h}$. Sample moisture content during the air-drying process was gravimetrically determined from the sample initial moisture content (before air-drying process). Sample weight was measured using a semi-analytical balance. Weighting intervals of $15 \mathrm{~min}$ were used during the first hour of processing, $30 \mathrm{~min}$ for the next $2 \mathrm{~h}$, and then $1 \mathrm{~h}$ until the dynamic equilibrium between the sample moisture content and drying air humidity was reached when the sample weight became constant.

The drying kinetics was studied by observing the drying curves for the considered air temperature and velocities.

\subsection{Modelling of drying kinetics curves}

For model evaluation, a nonlinear regression procedure was used, for both models (Eqs. (5) and (6)), using the statistical package Statistica 5.0 (Statistica, 1995). The modelling was characterized by the average relative error $E$ (Eq. (7)) calculation and the determination coefficient $R^{2}$.
$E(\%)=\frac{1}{N} \sum_{i=1}^{N}\left|\frac{V_{\mathrm{E}}-V_{\mathrm{P}}}{V_{\mathrm{E}}}\right| 100$

where $N$ is the number of experimental data, $V_{\mathrm{E}}$ is the experimental value and $V_{\mathrm{P}}$ is the calculated value.

\section{Results and discussion}

\subsection{Air drying kinetics of fresh and osmotically pre- dehydrated fruit}

In Fig. 1, the influence of the air velocity is shown at two temperatures $\left(40\right.$ and $\left.60{ }^{\circ} \mathrm{C}\right)$. By observing the drying curves at $40{ }^{\circ} \mathrm{C}$ (Fig. 1(a)), it seems like the air velocity did not markedly influence the drying kinetics for either osmosed and fresh papaya cubes. However, its influence on drying kinetics becomes more accentuated at $60{ }^{\circ} \mathrm{C}$ (Fig. 1(b)). At this temperature, the increasing of the air velocity from 1.25 to $3.25 \mathrm{~m} / \mathrm{s}$ caused a decrease on final product drying time (samples with $30 \%$ wet basis moisture content or $\sim 0.035$ dimensionless moisture ratio value). This fact was more pronounced for fresh papaya drying.

In agreement with Fig. 2, the strong influence of drying air temperature at two air velocities (1.25 and $3.25 \mathrm{~m} / \mathrm{s}$ ) is readily observed, as there is a very rapid decline in dimensionless moisture ratio $M$ at $60{ }^{\circ} \mathrm{C}$ compared to drying at $40{ }^{\circ} \mathrm{C}$. This statement was more evident at $3.25 \mathrm{~m} / \mathrm{s}$ and for fresh papaya drying. However, these drying curves show some convergence after $400 \mathrm{~min}$ of drying, and as equilibrium conditions are approached. With increase in the air temperature the drying curve becomes more accentuated. This fact caused the reduction of the final product drying time.

The physical and chemical changes in the fruit cubes during osmosis caused differences in the drying rate in the subsequent air-drying process when compared to fresh fruit cubes as observed in Figs. 3 and 4.
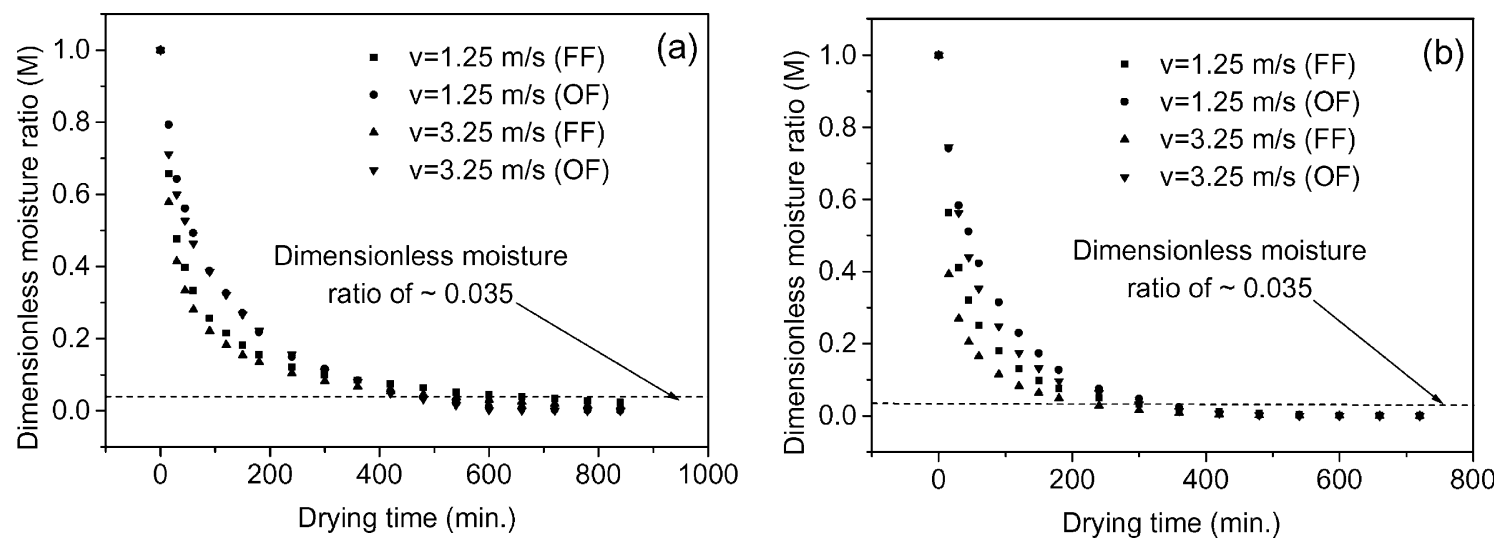

Fig. 1. Effect of the air velocity at (a) $40{ }^{\circ} \mathrm{C}$ and (b) $60{ }^{\circ} \mathrm{C}$, on drying process of fresh (FF) and osmosed papaya (OF). 

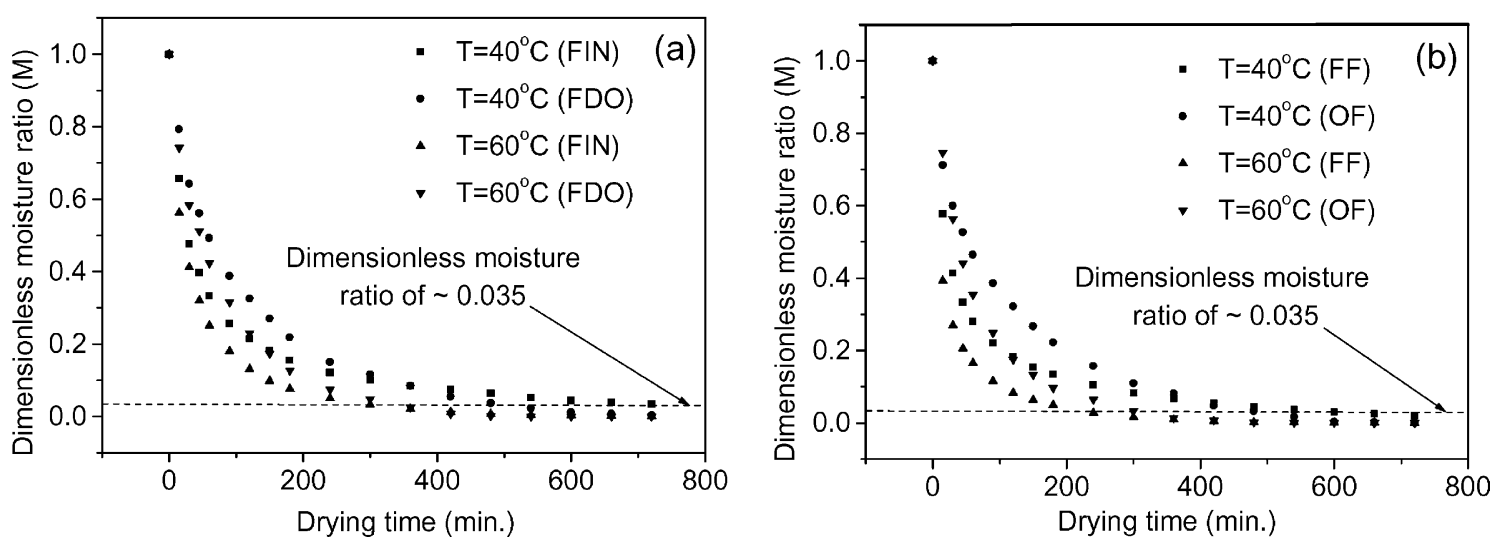

Fig. 2. Effect of the air temperature at (a) $1.25 \mathrm{~m} / \mathrm{s}$ and (b) $3.25 \mathrm{~m} / \mathrm{s}$ on drying time of final product for fresh (FF) and osmosed (OF) papaya.
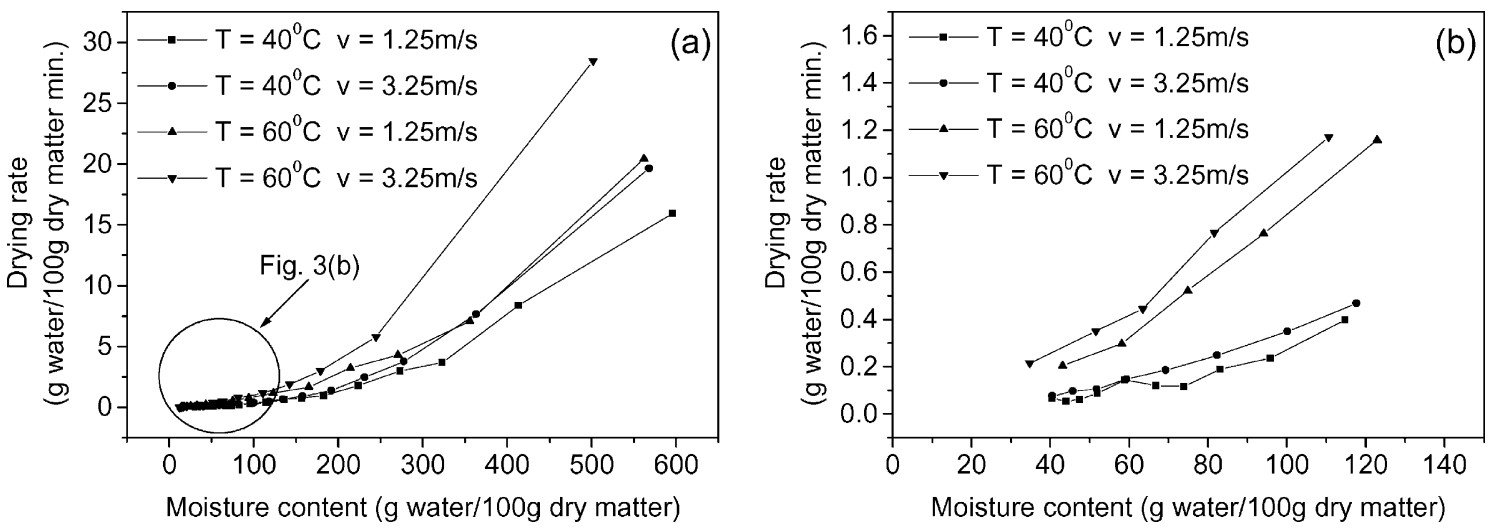

Fig. 3. Drying rate curves for fresh papaya cubes.
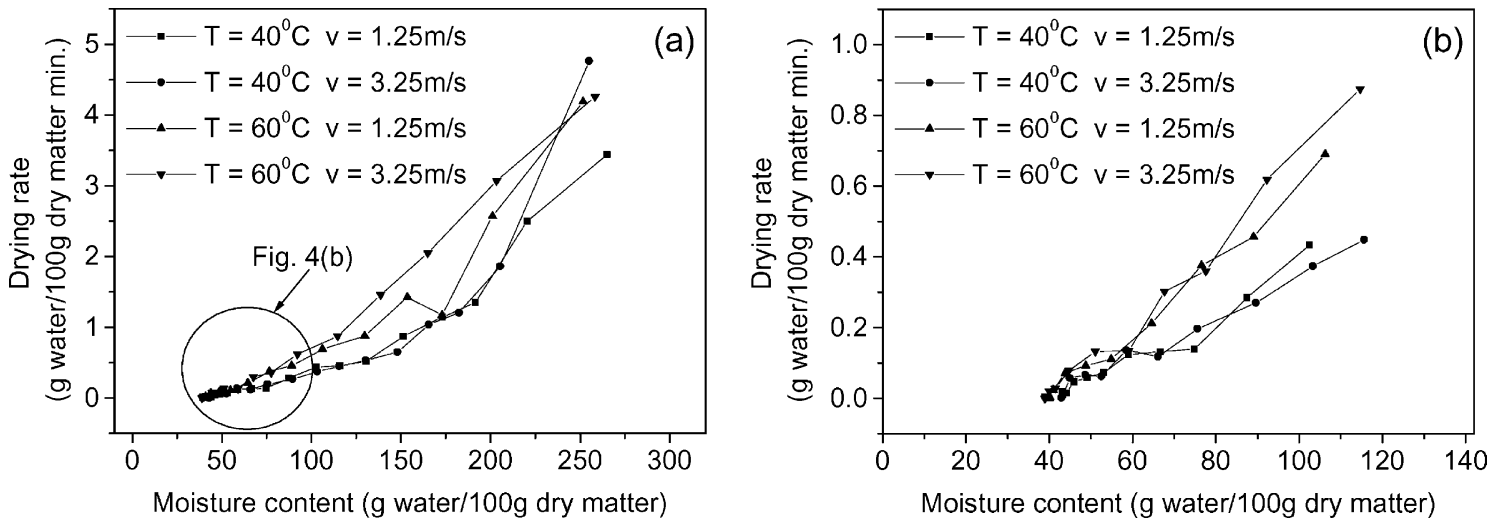

Fig. 4. Drying rate curves for osmosed papaya samples.

Comparing Figs. 3(a) and 4(a), it could be observed that drying rates were highest at the beginning of drying when moisture content was the greatest, with fresh cubes displaying the highest initial drying rates. In the early period of drying there was a rapid decline in the drying rate for both types of cubes (osmosed and nonosmosed). After this period of rapid decline in the drying rate, and below a certain critical moisture content in the falling rate period (e.g. $1.00 \mathrm{~g}$ water/g dry matter), the drying rate curves continue to decline, but more gradually and in a near linear fashion to equilibrium conditions. In fact below this critical moisture content, the differences in equivalent drying rates between fresh and osmosed cubes become small and obscure. However, closer examination of the drying rate experimental data for values below a critical moisture content of $1.00 \mathrm{~g}$ 
water/g dry matter (Figs. 3(b) and 4(b)) shows untreated papaya having higher drying rates compared to osmosed papaya.

Fig. 3(a) shows that, at the beginning of drying process of fresh papaya, both air velocity and air temperature strongly influenced drying rate, i.e. the increase of these variables caused an increase in drying rate. However, close to the end of drying (Fig. 3(b)), the air temperature had an effect upon drying rate higher than the effect of air velocity. For osmosed papaya drying (Fig. 4(a) and (b)), the influence of the air temperature was higher than the influence of the air velocity, in the beginning and close to the end of drying process.

The observed differences between fresh and osmosed papaya drying rates may be related to the solute uptake that occurred in the osmotic process which resulted in an increase in the internal resistance to mass transfer, as observed by Rahaman and Lamb (1991) for pineapple, Karathanos et al. (1995); Nieto, Salvatori, Castro, and Alzamora (1998) for apple. Mazza (1983), working with carrot, attributed these lower rates to the depression of water vapour pressure in the product due to dissolved sugar and the impairment of heat transfer and the crystallization of sucrose during the drying process. Nieto, Castro, and Alzamora (2001), working with mango, attributed the changes in moisture diffusivity property to the increased resistance to water flux caused by shrinkage, solid uptake and/or starch gelatinization and protein - carbohydrate mucilage degradation.

\subsection{Modelling of drying kinetics of fresh and osmosed papaya cubes}

Figs. 5 and 6 show the mathematical modelling of the drying kinetics experimental data using Eqs. (5) and (6) for fresh and osmosed papaya cubes at both studied air temperatures and velocities.

Table 1 shows Page's parameters for fresh FF and osmosed OF papaya samples. As expected, Page's equation gave a good fit to the experimental data. The calculated average relative error varied from $2.3 \%$ to $8.6 \%$. It was observed that, for osmosed papaya, the drying constant $K$ was higher at $40{ }^{\circ} \mathrm{C}$. It was expected that the drying constant was higher at higher temperatures,
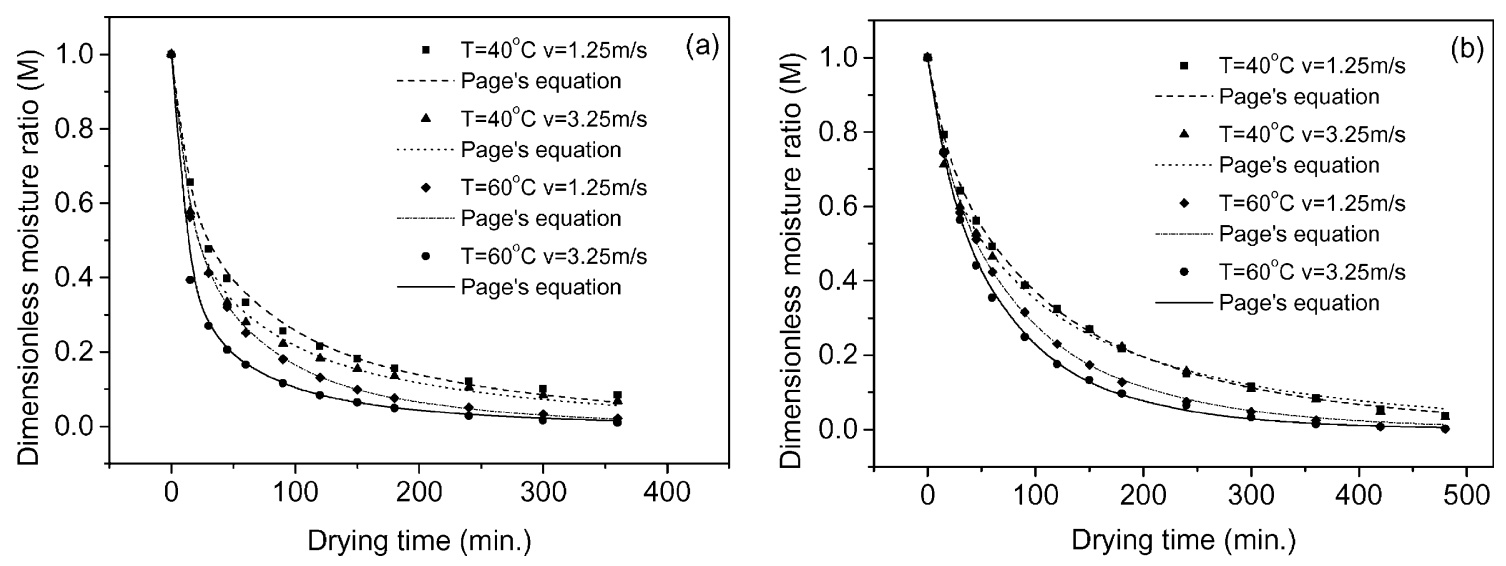

Fig. 5. Modelling of drying curves using Page's equation for (a) fresh and (b) osmosed papaya cubes.
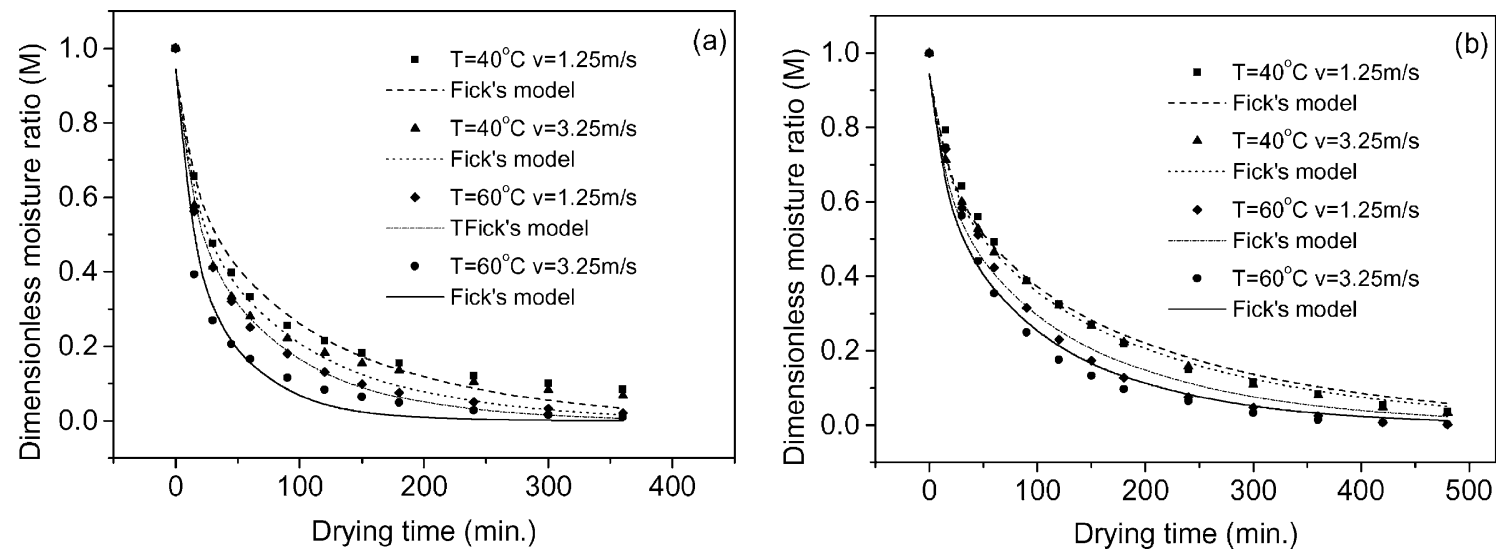

Fig. 6. Modelling of drying curves using the diffusional model for (a) fresh and (b) osmosed papaya cubes. 
Table 1

Page's equation parameters

\begin{tabular}{|c|c|c|c|c|c|c|c|c|c|}
\hline$T_{\mathrm{db}}\left({ }^{\circ} \mathrm{C}\right)$ & $v(\mathrm{~m} / \mathrm{s})$ & $K_{\mathrm{FF}}$ & $K_{\mathrm{OF}}$ & $B_{\mathrm{FF}}$ & $B_{\mathrm{OF}}$ & $R_{\mathrm{FF}}^{2}$ & $R_{\mathrm{OF}}^{2}$ & $E_{\mathrm{FF}}(\%)$ & $E_{\mathrm{OF}}(\%)$ \\
\hline \multirow[t]{2}{*}{40} & 1.25 & 0.113 & 0.037 & 0.542 & 0.717 & 0.995 & 0.999 & 6.8 & 4.0 \\
\hline & 3.25 & 0.162 & 0.056 & 0.490 & 0.639 & 0.997 & 0.998 & 6.4 & 8.3 \\
\hline \multirow[t]{2}{*}{60} & 1.25 & 0.115 & 0.036 & 0.601 & 0.776 & 0.999 & 0.999 & 3.1 & 8.2 \\
\hline & 3.25 & 0.260 & 0.037 & 0.474 & 0.803 & 0.999 & 0.999 & 2.3 & 8.6 \\
\hline
\end{tabular}

$T_{\mathrm{db}}$ is the dry bulb temperature.

Table 2

Fick's equation parameters

\begin{tabular}{|c|c|c|c|c|c|c|c|}
\hline$T_{\mathrm{db}}\left({ }^{\circ} \mathrm{C}\right)$ & $v(\mathrm{~m} / \mathrm{s})$ & $D_{\text {eff FF }}\left(\mathrm{m}^{2} / \mathrm{s}\right)$ & $D_{\text {eff OF }}\left(\mathrm{m}^{2} / \mathrm{s}\right)$ & $R_{\mathrm{FF}}^{2}$ & $R_{\mathrm{OF}}^{2}$ & $E_{\mathrm{FF}}(\%)$ & $E_{\mathrm{OF}}(\%)$ \\
\hline \multirow[t]{2}{*}{40} & 1.25 & $1.72 \times 10^{-9}$ & $1.03 \times 10^{-9}$ & 0.982 & 0.985 & 17.0 & 11.7 \\
\hline & 3.25 & $2.21 \times 10^{-9}$ & $1.11 \times 10^{-9}$ & 0.974 & 0.995 & 25.4 & 7.8 \\
\hline \multirow[t]{2}{*}{60} & 1.25 & $2.71 \times 10^{-9}$ & $1.48 \times 10^{-9}$ & 0.994 & 0.982 & 18.5 & 27.2 \\
\hline & 3.25 & $4.78 \times 10^{-9}$ & $1.78 \times 10^{-9}$ & 0.983 & 0.979 & 29.5 & 26.5 \\
\hline
\end{tabular}

as observed for fresh samples, because it represents the water diffusion velocity in the material. Park, Bin, Brod, and Park (2002), working with pear D'anjou cubes, noted that both Page's equation parameters did not exhibit a trend with increase in temperature at constant osmotic solution concentration. However, the air velocity seems to have some influence on drying constants $\left(K_{\mathrm{FF}}\right.$ and $\left.K_{\mathrm{OF}}\right)$ because they increased with air velocity at both temperatures.

Fick's parameters for fresh $\mathrm{FF}$ and osmosed OF papaya cubes are shown in Table 2. The effective diffusivities of water calculated using a dimensionless moisture ratio (Eq. (5) for the first 15 terms of the series) were higher for fresh fruits than those for osmosed samples and varied from $1.72 \times 10^{-9}$ to $4.78 \times 10^{-9} \mathrm{~m}^{2} / \mathrm{s}$ for fresh papayas and $1.03 \times 10^{-9}$ to $1.78 \times 10^{-9} \mathrm{~m}^{2} / \mathrm{s}$ for osmosed fruits. The average relative error values calculated for Fick's equation varied from $7.8 \%$ to $29.5 \%$.

Comparison of diffusivities reported in the literature is difficult because of the different estimation methods and models employed together with the variation in food composition and physical structure. Simal, Deyá, and Rosselló (1997) working with apple cubes found that $D_{\text {eff }}$ was $2.00 \times 10^{-10} \mathrm{~m}^{2} / \mathrm{s}$ at $30^{\circ} \mathrm{C}$ and $1.00 \times 10^{-9}$ $\mathrm{m}^{2} / \mathrm{s}$ at $90^{\circ} \mathrm{C}$. $D_{\text {eff }}$ values of osmosed and non-osmosed pineapples were found by Rahaman and Lamb (1991) and varied from $1.62 \times 10^{-10}$ to $1.25 \times 10^{-9} \mathrm{~m}^{2} / \mathrm{s}$.

Table 2 shows that, both air temperature and velocity increasing favoured the mass transfer process and, consequently, the increase in effective water diffusivity for both fresh and osmosed papayas, but their effects were more accentuated for fresh papaya drying.

According to Park, Vohnikova, and Brod (2002), on convective drying, effective diffusivities are obtained considering a negligible external resistance of mass transfer (corresponding to boundary layer), though the effect of air velocity on heat transfer is relevant as could be observed by the results found in this work.

\section{Conclusions}

Increase in air temperature and air velocity caused a reduction of final product drying time, but this fact was more pronounced for the drying process of fresh papaya.

Both air velocity and air temperature markedly influenced drying rate for fresh papaya cubes at the beginning of drying. Close to the equilibrium condition, only the air temperature affected the drying rate. The drying rate experimental data, for values below a critical moisture content of $1.00 \mathrm{~g}$ water/g dry matter, showed untreated papaya having higher values compared to osmosed papaya.

The observed differences between fresh and osmosed papaya drying rates may be related to the increase in the internal resistance to water movement caused mainly by shrinkage and solid uptake during the osmotic pretreatment.

Page's model showed a good fit to the experimental data and the calculated average relative errors were below 9\%. Page's equation parameters did not exhibit a clear trend with increase in air temperature, but the air velocity seemed to have some influence on drying constant because they increased with air velocity at both temperatures.

The increase of air temperature and air velocity gave an increase in effective water diffusivity values and this statement was more evident for the drying of fresh fruit. The effective diffusivities of water calculated from the diffusional model were higher for fresh fruits than those for osmosed samples and varied from $1.72 \times 10^{-9}$ to $4.78 \times 10^{-9} \mathrm{~m}^{2} / \mathrm{s}$ for fresh papayas and $1.03 \times 10^{-9}$ to 
$1.78 \times 10^{-9} \mathrm{~m}^{2} / \mathrm{s}$ for osmosed fruits. In general, $D_{\text {eff }}$ values found in this work were higher than those reported in literature for fruit drying.

\section{Acknowledgement}

We acknowledge FAPESP (The State of São Paulo Research Foundation).

\section{References}

Barbanti, D., Mastrocola, D., \& Severini, C. (1994). Air drying of plums. A comparison among twelve cultivars. Sciences des Aliments, 14, 61-73.

Crank, J. (1975). The Mathematics of Diffusion (second ed). Oxford: Claredon Press.

Jayaraman, K. S., \& Das Gupta, D. K. (1992). Dehydration of fruits and vegetables: recent developments in principles and techniques. Drying Technology, 10(1), 1-50.

Karathanos, V. T., Kostaropoulos, A. E., \& Saravacos, G. D. (1995) Air-drying of osmotically dehydrated fruits. Drying Technology, 13(5-7), 1503-1521.

Lenart, A. (1996). Osmo-convective drying of fruits and vegetables: technology and application. Drying Technology, 14(2), 391-413.

Lerici, C. R., Pinnavaia, T. G., Dalla Rosa, M., \& Bartolucci, L. (1985). Osmotic dehydration of fruit: influence of osmotic agents on drying behaviour and product quality. Journal of Food Science, 50, 1217-1219, 1216.

Mazza, G. (1983). Dehydration of carrots. Effects of pre-drying treatments on moisture transport and product quality. Journal of Food Technology, 18, 113-123.

Nieto, A. B., Castro, M. A., \& Alzamora, S. M. (2001). Kinetics of moisture transfer during air drying of blanched and/or osmotically dehydrated mango. Journal of Food Engineering, 50, 175-185.

Nieto, A. B., Salvatori, D. M., Castro, M. A., \& Alzamora, S. M. (1998). Air drying behavior of apples as affected by blanching and glucose impregnation. Journal of Food Engineering, 36, 63-79.
Page, G. E. (1949). Factors influencing the maximum rates of air drying shelled corn in thin layers. M.Sc. Thesis, USA. Purdue University, Indiana.

Park, K. J., Bin, A., Brod, F. P. R., \& Park, T. H. K. B. (2002). Osmotic dehydration of pear D'anjou (Pyrus communis L.). Journal of Food Engineering, 52, 293-298.

Park, K. J., Vohnikova, Z., \& Brod, F. P. R. (2002). Evaluation of drying parameters and desorption isotherms of garden mint leaves (Mentha crispa L.). Journal of Food Engineering, 51, 193199.

Pokharkar, S. M., Prasad, S., \& Das, H. (1997). A model for osmotic concentration of banana slices. Journal Food Science Technology, 34(3), 230-232.

Rahaman, M. D. S., \& Lamb, J. (1991). Air drying behaviour of fresh and osmotically dehydrated pineapple. Journal of Food Process Engineering, 14, 163-171.

Rodrigues, A.C.C. (1999). Influência dos aditivos na obtenção de mamão desidratado osmoticamente. Campinas. M.Sc. Thesis, Brazil, State University of Campinas, College of Food Engineering, Campinas-SP.

Sankat, C. K., Castaigne, F., \& Maharaj, J. R. (1996). The air drying behaviour of fresh and osmotically dehydrated banana slices. International Journal of Food Science and Technology, 31, 123135.

Sereno, A. M., Moreira, R., \& Martinez, E. (2001). Mass transfer coefficients during osmotic dehydration of apple in single and combined aqueous solutions of sugar and salt. Journal of Food Engineering, 47, 43-49.

Simal, S., Deyá, E., \& Rosselló, C. (1997). Simple modelling of drying curves of fresh and osmotically pre-dehydrated apple cubes. Journal of Food Engineering, 33, 139-150.

Statistica for Windows 5.0. (1995). Computer program manual. StatSoft, Inc., Tulsa.

Torreggiani, D. (1993). Osmotic dehydration in fruit and vegetable processing. Food Research International, 26, 59-68.

Treybal, R. E. (1981). Drying. In Mass-Transfer Operations (third ed). NY: McGraw-Hill.

Van Arsdel, W. B. (1973). Drying phenomena. In W. B. Van Arsdel, M. J. Copley, A. I. Morgan Jr., Food dehydration (2nd ed.), vol. 1(3), AVI publishing Co., Westport, pp. 22-57. 